\title{
In Favor of [Fortis]: Evidence from Setswana and Sebirwa
}

\author{
Elizabeth Zsiga \\ Georgetown University
}

\section{Introduction: What do we want phonological features to do?}

Phonologists have long argued that there is a "canon" of phonological features: a closed set of "phonologically relevant properties" (Trubetzkoy 1939:36) that are useful for delimiting contrasts, defining classes of sounds targeted by phonological generalizations, and characterizing alternations. Clements et al. (2011) list four generally-accepted criteria for admittance to this canon: 1) phonetic definition or motivation, 2) recurrence across languages, 3 ) formal simplicity, and 4) comprehensiveness (that is, success in accounting for the data). It is perhaps remarkable how often we can find features that meet all four criteria. More interesting, however, are the cases where there are tradeoffs. The most successful feature set for a given set of data (winning on comprehensiveness) may sacrifice simplicity or cross-linguistic recurrence. Formal simplicity and recurrence may require a less direct phonetic definition. Clements et al. consider in detail the features necessary to define tonal contrasts and alternations and reach the conclusion that it is impossible to define features for tone that are both formally simple and cross-linguistically relevant. If there are such features, they argue, the features must be quite abstract rather than transparently related to phoneticallydefined pitch patterns. Hyman $(2010,2011)$ makes a similar argument.

Mielke (2008) addresses the potential conflict between comprehensiveness and recurrence, and shows that no canon of features is completely successful. A set of features that might be perfect for one language is not necessarily useful for any others. Mielke analyzed a corpus of 628 languages containing 6077 "phonologically active classes," and compared the ability of different feature sets to account for the data. Figure 1 graphs the result for the most successful feature set, the one proposed in Chomsky and Halle (1968).

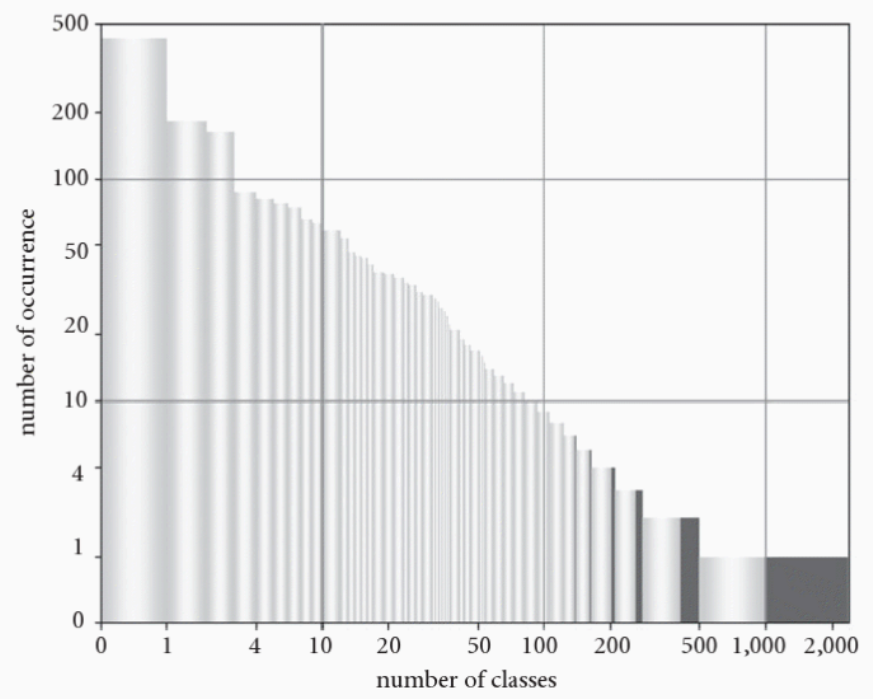

Figure 1. The distribution of frequent and infrequent natural and unnatural classes, defined by the features proposed by Chomsky and Halle (1968). From Mielke 2008:157.

\footnotetext{
* I would like to thank my colleague One Tlale Boyer and research assistants Jon Havenhill and Stacy Petersen. This research was supported by grants from the National Science Foundation (BCS-1052937) and from Georgetown University. 
Light-colored bars indicate "natural" classes, those that are successfully defined by the canonical feature set, and dark bars indicate "unnatural" classes, those that are not so captured. The height of the bars indicates how frequent that class is across the corpus (both axes are logarithmic). The question we have to ask of these results, as pointed out by Cohn (2011), is "Does Figure 1 represent success or failure?" All of the most frequent classes, and almost all of those that occur more than two or three times, are well defined by the canonical feature set. There is, however, a large number of "one-off" classes and alternations that are not defined by the feature set in any straightforward way. Mielke argues that language learners will create whatever phonological features they need to account for the data their language presents to them, and that the feature set is therefore not closed.

It would be a mistake, however, to throw the baby out with the bathwater, and conclude that there is no point in trying to define a generally valid feature set at all. Figure 1 shows that most of what happens in a given language happens in many other languages as well. We should not give up on what I take to be one of the central goals of phonology: to describe cross-linguistic sound patterns. Whether these patterns arise due to historical pressures, or phonetic motivation at the level of the individual learner, we want to be able to say, at a general level, "What are phonologies like?" Our feature set should be part of the answer.

To that end, this paper argues for a return to the feature [fortis]. Trubetzkoy (1939) included the [fortis/lenis] distinction among the "phonologically relevant properties" available to languages, and I will argue that Trubetzkoy was right. In returning this feature to the canon we will need to allow more abstraction in terms of phonetic motivation, but we may gain quite a lot in simplicity, comprehensiveness, and recurrence. We may say something real and general about cross-linguistic variation that is lost if the focus on phonetic realization is emphasized above other criteria.

Trubetzkoy (1939) defined fortis consonants as "strong" in "degree of resistance," with both aspirated and geminate consonants counted as [fortis]. Jakobson, Fant, and Halle (1952), pushing to make the feature set as compact as possible, substituted the feature [tense/lax], with a broader (but still generally phoneticallybased) definition, in terms of the amount of articulatory energy expended. For the most part, the same consonants that were [fortis] were now [tense], but unlike [fortis], [tense] could also be used to define sets of vowels. Chomsky and Halle (1968) took over the [tense/lax] definition. Kohler (1984) attempted a resurrection of the feature [fortis], defining the feature as incorporating both length and "power," but his proposal was not widely accepted. Rather, in the decades following, "tense" was dropped as a feature for consonants, in favor of geometrical representations for geminates, and phonetically explicit features for laryngeal contrasts, either [voice], [spread glottis] and [constricted glottis] (Lombardi 1991), or stiff/slack vocal folds (Halle and Stevens 1971).

However, laryngeal contrasts and configurations are multiple and interdependent (Kingston and Diehl 1994, Avery and Idsardi 2001). Since multiple dimensions of laryngeal configuration are phonetically controlled, it can be difficult to determine which dimensions are contrastive, and which are either passive or enhancing. As pointed out by proponents of "Laryngeal Realism" (Honeybone 2005), just because voicing or aspiration is phonetically present does not mean that the feature underlying the contrast is [voice] or [spread glottis]. Rather, a phonologist must consider the full range of positional variation to determine what the "real" dimensions of contrast are.

The question of the features that underlie positional variation in consonant voicing brings us to Setswana and Sebirwa, two Southern Bantu languages spoken in and around Botswana. Figure 2 shows representative productions of the phrase "S/he reads me" in Setswana (left) and "S/he counts me" in Sebirwa (right), both containing the cognate verb written "bala" and pronounced [bala] in isolation. The Sebirwa phrase can be straightforwardly transcribed as [mpala], containing a post-nasal voiceless unaspirated stop with a very short VOT and typically weak burst. (The interesting question is why [bala] in isolation should become [pala] in post-nasal position.) The Setswana phrase contains a nasal, followed by voiced obstruent closure, followed by a strong, possibly ejective, burst: [mbp'ala]? In the sections that follow, I will marshal the phonological and phonetic evidence to argue that the Sebirwa obstruent is best characterized as [-voice], but that the Setswana obstruent can only be accurately characterized as [fortis]. 

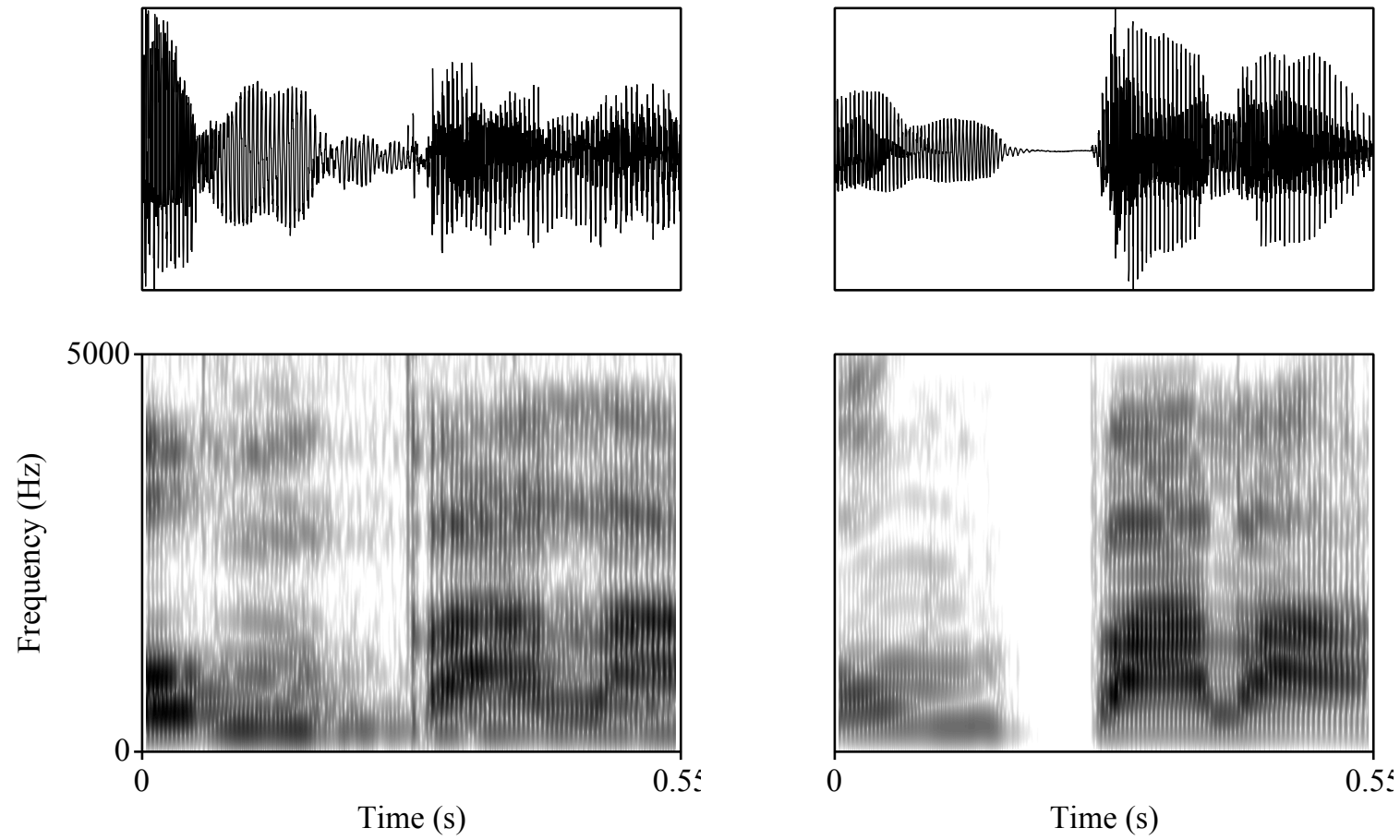

Figure 2. Left: "S/he reads me" in Setswana. Right: "S/he counts me" in Sebirwa. Both from /bala/ "read/count."

\section{The problem of Setswana}

Figure 3 shows the Setswana consonant inventory (from Zsiga and Tlale 2017). The inventory is large and interesting, with labio-coronal fricatives and affricates, and secondary labialization (see Zsiga et al. 2018). Here, we concentrate on the obstruent stops, where the inventory is not symmetric. There is no voiced velar stop in the native vocabulary, and [d] does not contrast with [t], but occurs only as an allophone of /1/ before high vowels (see Gouskova et al. 2011 and Boyer and Zsiga 2013 for further discussion and examples). The only syllable types allowed are $\mathrm{CV}, \mathrm{V}$, or a syllabic nasal, and stress is consistently penultimate.

\begin{tabular}{|c|c|c|c|c|c|c|}
\hline & bilabial & alveolar & alv.pal. & velar & glottal & labicoronal \\
\hline stop & $p p^{h} b$ & $\begin{array}{c}\mathrm{t} \mathrm{t}^{\mathrm{h}}(\mathrm{d}) \\
\mathrm{t}^{\mathrm{w}} \mathrm{t}^{\mathrm{tw}}\end{array}$ & & $\begin{array}{c}\mathrm{k} \mathrm{k}^{\mathrm{h}} \\
\mathrm{k}^{\mathrm{w}} \mathrm{k}^{\mathrm{hw}}\end{array}$ & & \\
\hline fricative & $\phi$ & $\underset{\mathrm{s}^{\mathrm{w}}}{\mathrm{s}}$ & $\int$ & $\underset{\mathrm{x}^{\mathrm{w}}}{\mathrm{x}}$ & $\mathrm{h}$ & $\widehat{\phi \int}$ \\
\hline affricate & & 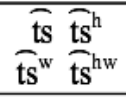 & $\widehat{\mathrm{t} \int} \overline{\mathrm{t} \mathrm{f}^{\mathrm{h}}} \overline{\mathrm{d} 3}$ & $\begin{array}{c}\mathrm{k} \overline{\mathrm{X}}^{\mathrm{h}} \\
\mathrm{k} \overline{\mathrm{X}}^{\mathrm{hw}}\end{array}$ & & $\widehat{\mathrm{p} \int} \widehat{\mathrm{p} \int^{\mathrm{h}}} \widehat{\mathrm{b}_{3}}$ \\
\hline nasal & $\mathrm{m}$ & $\begin{array}{c}n \\
n^{w}\end{array}$ & $\begin{array}{c}\mathrm{n} \\
\mathrm{n}^{\mathrm{w}}\end{array}$ & $\begin{array}{c}\mathrm{y} \\
\mathrm{n}^{\mathrm{w}}\end{array}$ & & \\
\hline approx. & $(\beta)$ & $\begin{array}{c}\mathrm{r} 1 \\
\mathrm{r}^{\mathrm{w}} 1^{\mathrm{w}}\end{array}$ & & & & \\
\hline
\end{tabular}

Figure 3. Setswana consonant inventory. Allophones are shown in parentheses.

There is thus a three-way laryngeal contrast only for the bilabials. In terms of features, this set of contrasts is not at first glance problematic, as shown in Table 1. We seem to have plain, aspirated, and voiced 
consonants, consistent with a standard theory of privative [SG] and privative [voice]. The plain stops can be left unspecified.

\begin{tabular}{|l|l|l|}
\hline Orthographic & Phonetic & Feature \\
\hline $\mathrm{p}$ & plain voiceless & $\varnothing$ \\
\hline $\mathrm{ph}$ & aspirated & {$[\mathrm{SG}]$} \\
\hline $\mathrm{b}$ & voiced & {$[$ voice] } \\
\hline
\end{tabular}

Table 1. Features for Setswana stops, first pass.

We run into problems, however, when we look at the details of positional variation and phonetic realization. First, the "plain voiceless" stops are variably ejective. It is hard to state their distribution exactly, as the ejective release is sometimes weak, with very short VOT, and it may be impossible to tell if the voicelessness is due to glottal opening or glottal closing (Kingston 2005). We note, however, that the clearest ejectives are often found in unstressed and final syllables. The utterance in Figure 4, with three voiceless stops, is typical. In /paka/, the $/ \mathrm{k} /$ is clearly ejective, the initial /p/ might be. The final syllable, however, is completely reduced, with almost nothing left but a really strong ejective burst.

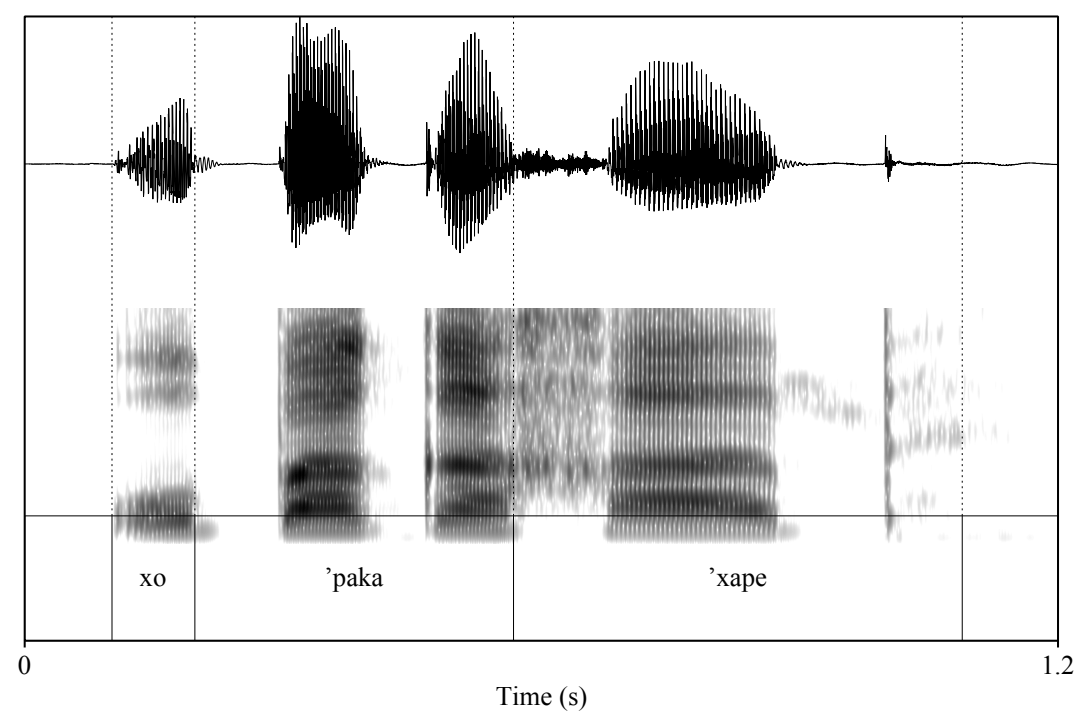

Figure 4. The phrase /xo paka xape/ "to carry again" in Setswana.

Phonologically, where do these ejectives come from? If the voiceless stops are underlyingly unspecified for laryngeal features, we need a theory of why glottal constriction is added, particularly in syllables that are otherwise not prominent. If the voiceless stops are underlyingly [CG], as we assumed in Gouskova et al. (2011), then we have a markedness paradox: there is no unmarked pole in the system of contrast. While the presence of these ejective stops has been noted in previous work, it is the voiced stops that have gotten the most attention.

Setswana is famous in the literature for its post-nasal alternations. Some examples from Gouskova et al. (2011) are shown in (1) and (2).

(1) Post-nasal fortition of continuants in Setswana

$\begin{array}{llll}\text { fula } & \text { shoot } & \mathrm{mp}^{\mathrm{h}} \text { ula } & \text { shoot me } \\ \text { supa } & \text { point at } & \mathrm{nts}^{\mathrm{h}} \text { upa } & \text { point at me } \\ \text { Japa } & \text { hit } & \mathrm{ng}^{\mathrm{h}} \text { apa } & \text { hit me } \\ \text { rata } & \text { love } & \mathrm{nt}^{\mathrm{h}} \text { ata } & \text { love me }\end{array}$


(2)

\begin{tabular}{llll}
\multicolumn{2}{l}{ Post-nasal devoicing of stops in Setswana } & \\
bala & read & mpala & read me \\
duba & knead & ntuba & knead me \\
pala & refuse & mpala & refuse me \\
tuba & wish harm on & ntuba & wish harm on me
\end{tabular}

Post-nasal fortition is common cross-linguistically, but, as noted by Hayes (1999), Pater (1999), Hyman (2001) and others, post-nasal devoicing is not supposed to happen. As these sources detail, aerodynamic considerations favor perseverative voicing from a nasal into a following oral closure, and thus crosslinguistically, languages prefer [mb] to [mp]. In Setswana, however, underlying $/ \mathrm{mb} /$ is described as becoming [mp], as in (2) above, a change from an unmarked to marked sequence that is apparently phonetically unmotivated. Further complicating the situation, the output of post-nasal "strengthening" (combining the data in (1) and (2)) is not a natural class. The problem this poses for feature theory was noted by Chomsky and Halle (1968: 401).

A different type of example is provided by phonological processes which reflect the effects of a coherent system of rules. Thus, in Tswana (Cole, 1955; see also Fudge, 1967), in position after nasals voiced stops become ejectives, nonobstruent continuants become voiceless aspirated plosives, and obstruent continuants become voiceless aspirated affricates. Cole rightly subsumes these changes under the single heading of "strengthening." In the present framework, however, there is no device available that would allow us to bring out formally the fact that these three processes are somehow related.

The Setswana alternation between [b] and [mp] has been much discussed in recent literature in debates over whether all phonological alternations must be phonetically grounded. Hyman (2001) argues that the alternation is one of devoicing, and that it arose in Setswana from a historical stage in which Proto-Bantu voiced stops lenited to sonorants in non-post-nasal position, while the remaining post-nasal stops devoiced, not due to their post-nasal position, but due to a general prohibition on voiced obstruents. At a later stage, $[\beta]$ underwent fortition to $[\mathrm{b}]$ in initial position, resulting in the phonetically unnatural $[\mathrm{b}] /[\mathrm{mp}]$ alternation. Gouskova et al. (2011) agree that the alternation is devoicing, but argue that devoicing can be a kind of fortition, so that the alternation can be characterized as phonetically natural. Fieldwork and production studies (Coetzee et al. 2007, 2010, Sole et al. 2010, Boyer and Zsiga 2012) find variability in application and failure to generalize (for example, to [n-dodza] avoid me or [m-фonela] phone me), leading to the question of whether the alternation is productive phonology at all. In this paper, it will be argued that, however the alternation arose in Setswana, it is not about voicing.

\section{Setswana data and analysis}

This section summarizes phonetic data reported in Boyer and Zsiga (2013). For this study, 27 speakers of the Sengwato dialect of Setswana (spoken in the northeast of Botswana, in and around the town of Shoshong) participated in a production and perception experiment (see Boyer and Zsiga 2013 for details). For the production experiment, speakers were recorded reading three repetitions of a set of verbs exemplifying all the consonants of the Setswana inventory in three contexts: word-initial in isolation, wordinitial but phrase-medial (and thus intervocalic), and post-nasal. Voice onset time (VOT), duration of voicing, and closure duration (in intervocalic and post-nasal position) were measured using Praat (Boersma and Weenink 2017). The stops were matched for vowel quality within place of articulation: the labial stops occurred before $/ \mathrm{a} /$ or $/ \mathrm{e} /$, and the alveolar stops occurred before $/ \mathrm{i} /$ or $/ \mathrm{u} /$. (The distribution of $/ \mathrm{t} /$ is not restricted by vowel context, but [d] occurs only as an allophone of /1/ before high vowels.) All measured syllables were stressed.

The perception study consisted of two tasks. For the discrimination task, speakers were presented with two words that were either two tokens of the same word, or two words that differed only in initial consonant, and were asked to judge "same" or "different." In the identification task, speakers were presented with words in isolation that had been excised from their original context, and were asked to identify the lexical item.

The aspirated stops showed little positional variation, with approximately $70 \mathrm{~ms}$ VOT in all positions, and some perseverative voicing into the closure in intervocalic and post-nasal positions. The graphs in Figures 5,6 , and 7 show the acoustic measures for $/ \mathrm{b} /, / \mathrm{p} /, / \mathrm{d} /$, and $/ \mathrm{t} /$. 


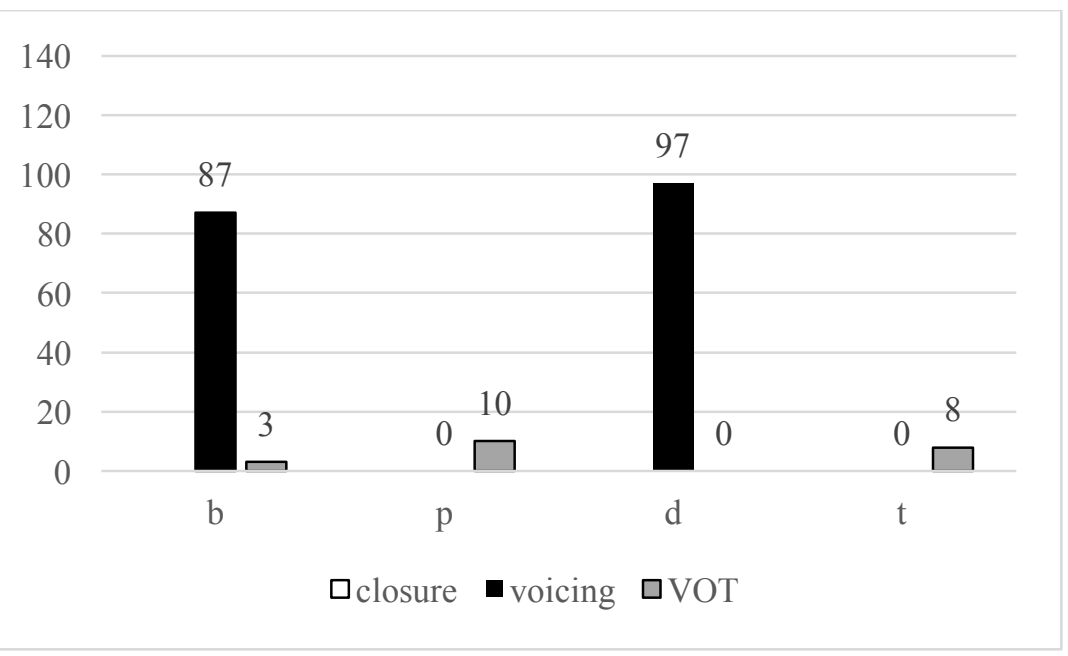

Figure 5. Duration (ms) of stops in phrase-initial position in Setswana. Data from Boyer and Zsiga (2013).

In phrase-initial position, the data show a contrast between pre-voicing and very short-lag positive VOT. In this position, closure duration cannot be measured. Additionally, at least some of the initial voiced stops showed formant structure and no bursts, so are probably better described as sonorants. Only the stop realizations are included in the graph. We also judged that the initial voiceless stops were often weakly ejective (Kingston 2005). Participants in the perception study identified initial stops with $100 \%$ accuracy.

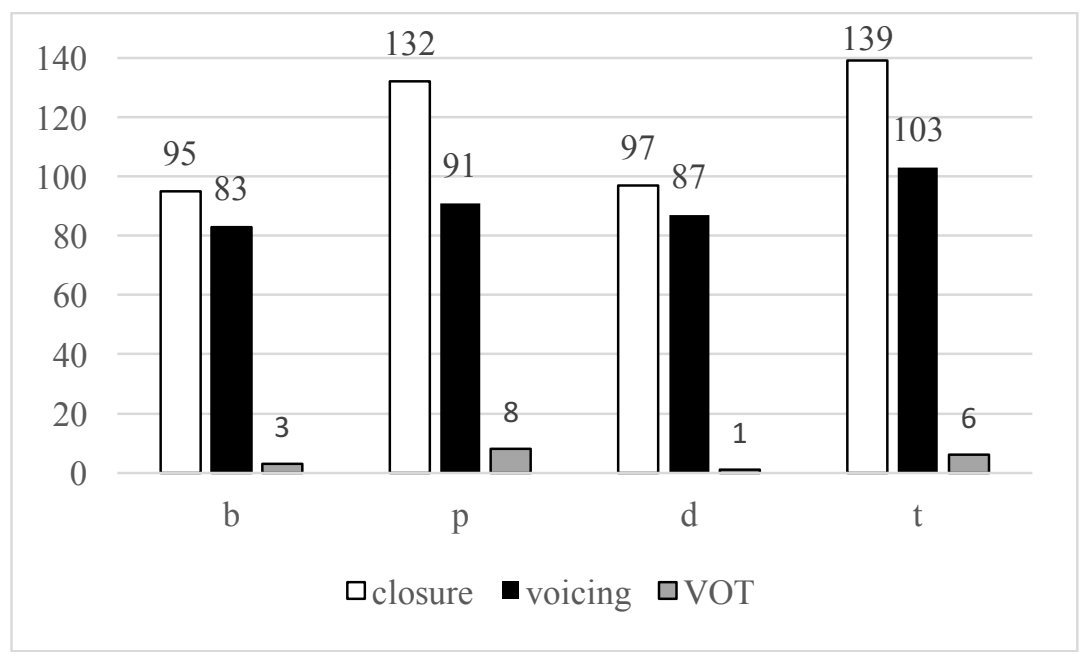

Figure 6. Duration (ms) of stops in word-initial phrase-medial (intervocalic) position in Setswana. Data from Boyer and Zsiga (2013).

In intervocalic position, as shown in Figure 6, the difference between "voiced" and "voiceless" stops is not in the amount of voicing, but rather in the length of the closure, and in a small difference in VOT. The voiceless stops are $40 \%$ longer than the voiced. More so than in initial position, $/ \mathrm{b} /$ is often realized as $[\beta]$, with no complete closure, though the graph shows stop realizations only. Again, participants in the perception study identified intervocalic stops with $100 \%$ accuracy.

Note that in Gouskova et al. (2011) we found [p] as an intervocalic allophone of /b/, but that was not the case in the study reported here. The difference is that in the earlier study, the intervocalic stops were in unstressed phrase-final syllables. In general, Setswana phrase-final syllables undergo significant weakening (as was seen in Figure 4). It is common, for example, to hear the pronunciation [xap] for /xape/ "again," or [sets ${ }^{\mathrm{w}} \mathrm{an}$ ] for /setswana/. Thus, devoicing of voiced stops in phrase-final syllables in Setswana can be 
analyzed along the lines proposed by Hayes (1984) for Russian devoicing: there is a laryngeal configuration that results in voicing for sonorants and devoicing for obstruents. Under this analysis, /'swaba\#/ can become ['s $\mathrm{s}^{\mathrm{w}}$ apa\#] if speakers do not make the laryngeal/airstream adjustment needed to create voicing in these weak syllables.

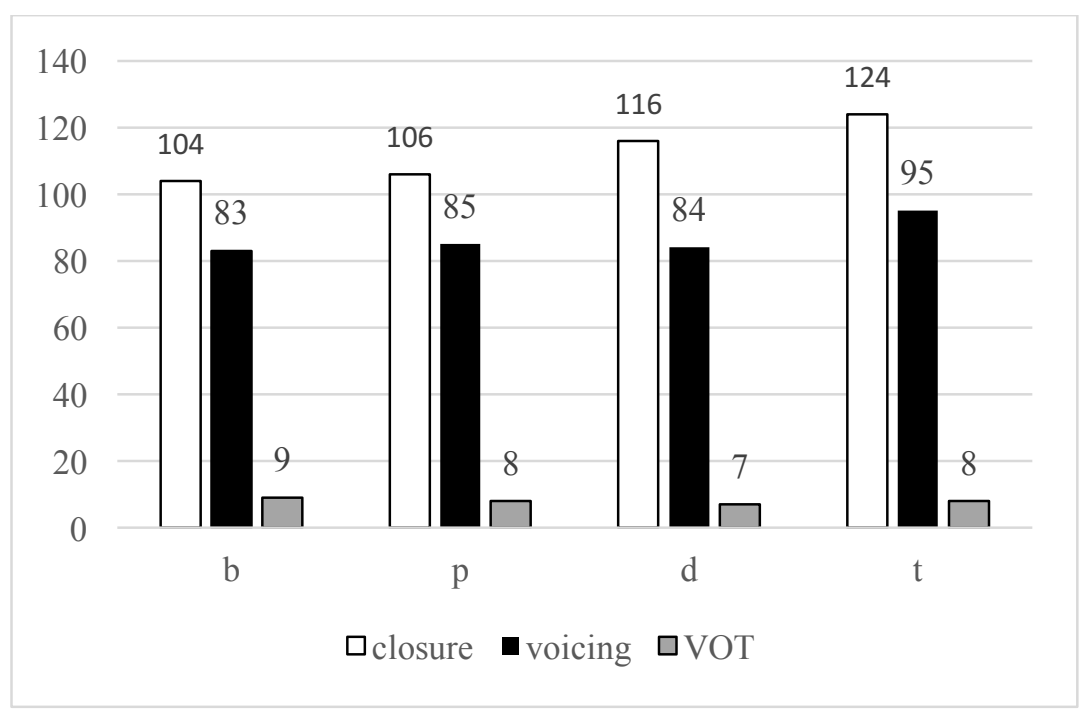

Figure 7. Duration (ms) of stops in post-nasal position in Setswana. Data from Boyer and Zsiga (2013).

In post-nasal position (Figure 7), the difference between voiced and voiceless stops is neutralized, as was confirmed by the perception study. Participants identified both /m+bala/ "read me" and /m+pala/ "refuse me" as "refuse me." As can be seen, however, in Figure 7, and in the example utterance in Figure 2, the closure is almost entirely voiced. There is definitely a post-nasal alternation, but it is not one of devoicing.

Table 2 summarizes the contextual realizations of the labial stops.

\begin{tabular}{|c|c|c|c|c|c|}
\hline orthographically & \#\#CV. &.$V C V \ldots$ & ...CV\#\# & $\mathrm{NCV}$ & feature \\
\hline $\mathrm{p}$ & $p$ or p' & $\mathrm{p}:$ & $\mathrm{p}^{\prime}$ & bp' & [fortis] \\
\hline $\mathrm{ph}$ & ph & ph & ph & bph & [fortis], [SG] \\
\hline$b$ & $\beta$ or $b$ & $\beta$ or $b$ & $b$ or $p$ & bp' & $\varnothing$ \\
\hline
\end{tabular}

Table 2. Contextual realizations of Setswana labial stops.

The conclusion is that, except for the possible exception of citation forms in isolation, voicing in Setswana is entirely passive. Speakers make no effort to cut off voicing in "voiceless" stops in inter-sonorant position, and no effort to promote voicing in "voiced" stops in phrase-final syllables. Instead, we see Trubetzkoy's definition of "strength" realized in different ways. The stop /p/ is long or ejective or both, and thus usually voiceless. The stop $/ \mathrm{b} /$ is short and weak, and thus usually voiced.

I would argue, then, that Setswana stops are not specified for voice at all, but with the features [fortis] and [spread glottis]. What the [fortis] consonanants have in common is not lack of voicing, but "strength" (Trubetzkoy 1939) and "resistance" Kohler (1984). For the fortis stops, speakers make a definite articulatory adjustment, either laryngeal or supralayrngeal or both, to create a strong occlusion, and thus a strong burst.

\section{In favor of [fortis]}

Using the features in Table 2 solves the problem noted by Chomsky and Halle (1968): the class of sounds that can occur in post-nasal position in Setswana (affricates, ejectives, and aspirated stops) is in fact a natural class. The set of post-nasal realizations is not an amalgam of [-continuant], [aspirated], and [-voice], but the natural class of [fortis] consonants. These features also solve the markedness paradox in the inventory. There 
is an unmarked member of the opposition, but it is $/ \mathrm{b} /$, not $/ \mathrm{p} /$. Thus, the feature [fortis] allows for an analysis that is both comprehensive and formally simple.

What about cross-linguistic recurrence? An obvious comparison is to Korean, for which the terms "fortis" and "lenis" are often informally applied. Jun (1996), among others, argues that the lenis stops of Korean undergo passive voicing, while the fortis stops are variably realized as geminate or ejective. Another point of comparison is Quechua. For this language, Gallaher (2011) argued that the ejective and aspirated stops form a natural class, for which she proposed the feature [+long VOT]. This feature could be subsumed by the more general feature [fortis], though the reverse is not the case, as the ejective stops of Setswana are very short lag. Other examples of fortis consonants suggested by Kohler (1984) and Trubetzkoy (1939) could be further investigated.

Is the feature [fortis] phonetically defined? A feature that can be realized as either length or glottal constriction is not articulatorily transparent. It appears to be parallel, however (in fact opposite), to the feature [sonorant]. The feature [sonorant] is defined (e.g., in Chomsky and Halle 1968) as having no build-up of pressure behind an occlusion. The release of pressure can be accomplished in different ways, for example by lowering the velum, lowering the sides of tongue, a short closure (as for a tap), or a more open constriction. The feature [fortis] could be similarly defined, as having greater build-up of pressure behind an occlusion (essentially following Kohler 1994), and this also could be realized in different ways, including larynx raising and longer constriction.

To summarize this section, Trubetzkoy was right: "strength" is a parameter languages use to create contrast and natural classes among consonants. We lose this generalization when we concentrate on the language-particular realizations of [strength]. This also means, however, that the debate about the naturalness of post-nasal "devoicing" in Setswana has been off-track. As Larry Hyman (p.c.) communicated to me after much discussion, if we're looking for post-nasal devoicing, we're looking at the wrong language. The postnasal alternation in Setswana is not about voicing at all.

We turn now to another language where it is.

\section{Comparison to Sebirwa: In favor of [voice]}

Setswana and Sebirwa are both Sotho-Tswana languages spoken in Botswana. Setswana is officially designated as the national language of Botswana, and is in widespread use across all media. It is spoken as a first language by about $80 \%$ of the population (a total of approximately 4.5 million native speakers), and is learned by all citizens of Botswana in elementary school. Sebirwa, in contrast, is not recognized as an official language and is not written. It is spoken by a small ethnic minority in the far eastern corner of Botswana (adjacent to the Sengwato dialect area). The phonetic data presented here (summarizing data reported in Zsiga and Boyer 2017) is based on fieldwork conducted in the village of Molalatau.

Sebirwa is critically endangered. The Botswana 2001 census lists 12,500 Sebirwa speakers, but (as noted by Zsiga and Boyer 2017), this is probably reporting ethnicity rather than language use. Ethnologue classifies Sebirwa as "in vigorous use among all generations," but we found no speakers under the age of 65 willing to self-identify as fluent speakers. Because the language is not spoken by adults of child-bearing age, no children are learning it. The one previous phonological description of Sebirwa in the literature is Chebanne (2000), which consists of a tentative inventory, historical notes, and a short phonological description based on phonetic data elicited from ten speakers, all older than 75 years. The Sebirwa consonant inventory is shown in Figure 8.

Sebirwa has the same syllable structure and stress pattern as Setswana, and many words are cognate. Like Setswana, Sebirwa uses labio-coronal fricatives (the aspect that first drew our attention to the language). The two langauges differ phonologically in important ways, however. Crucially, Sebirwa contrasts voiced and voiceless stops at all three places of articulation, as shown in Figure 8 and illustrated in (3). Further, both /d/ and /1/ occur freely with all vowels: compare Sebirwa [luma] "bite" with Setswana [duma].

\begin{tabular}{|c|c|c|}
\hline Cont & ive voi & irwa \\
\hline bala & count & pala \\
\hline dada & bind & tadza \\
\hline gada & stitch & kala \\
\hline
\end{tabular}




\begin{tabular}{|c|c|c|c|c|c|c|}
\hline & bilabial & alveolar & alv.pal. & velar & glottal & labicoronal \\
\hline stop & $\mathrm{p} \mathrm{p}^{\mathrm{h}} \mathrm{b}^{\mathrm{b}}$ & $\begin{array}{cll}\mathrm{t} \mathrm{t}^{\mathrm{h}} & \mathrm{d} \\
\mathrm{t}^{\mathrm{j}} & \mathrm{t}^{\mathrm{j} j} & \mathrm{~d}^{\mathrm{w}}\end{array}$ & & $\begin{array}{l}\mathrm{k} \mathrm{k}^{\mathrm{h}} \mathrm{g} \\
\mathrm{k}^{\mathrm{w}} \mathrm{g}^{\mathrm{w}}\end{array}$ & & \\
\hline fricative & $\phi$ & $\begin{array}{cc}S & Z \\
s^{j} & Z^{w}\end{array}$ & $\int$ & & $\mathrm{h}$ & $\widehat{\Phi S}$ \\
\hline affricate & & $\widehat{\mathrm{ts}} \frac{\widehat{\mathrm{dz}}}{\mathrm{dz}^{\mathrm{w}}}$ & $\widehat{\mathrm{t}} \widehat{\mathrm{t} \mathrm{f}^{\mathrm{h}}} \widehat{\mathrm{d}} \widehat{\mathrm{s}}$ & & & $\widehat{\mathrm{p} \int} \widehat{\mathrm{p} \int^{\mathrm{h}}} \widehat{\mathrm{b}} \widehat{3}$ \\
\hline flap & & 1 & & & & \\
\hline nasal & $\mathrm{m}$ & $\begin{array}{c}n \\
n^{j} n^{w}\end{array}$ & $\mathrm{n}$ & $\begin{array}{c}\mathrm{y} \\
\mathrm{n}^{\mathrm{w}}\end{array}$ & & \\
\hline approx. & & $\begin{array}{l}\mathrm{rl} 1 \\
\mathrm{l}^{\mathrm{w}} \quad \mathrm{P}\end{array}$ & & & & \\
\hline
\end{tabular}

Figure 8. The Sebirwa consonant inventory. From Zsiga and Boyer (2017), based on Chebanne (2000) and subsequent fieldwork.

Based on the inventory in Figure 8, Sebirwa's three-way stop contrast can be described as plain vs. aspirated vs. voiced, as shown in Table 3. In this case, the features [voice] and [SG] will turn out to be correct.

\begin{tabular}{|l|l|l|}
\hline Orthographic & Phonetic & Feature \\
\hline $\mathrm{p}$ & plain & $\varnothing$ \\
\hline $\mathrm{ph}$ & aspirated & {$[\mathrm{SG}]$} \\
\hline $\mathrm{b}$ & voice & {$[$ voice] } \\
\hline
\end{tabular}

Table 3. Features for Sebirwa stops.

Chebanne specifically notes that there is no post-nasal devoicing in Sebirwa. According to Chebanne, the voiced stops of Proto-Birwa did not undergo lenition as did the voiced stops of Proto-Tswana, so the conditions for a sonorant/voiceless stop alternation never arose. Chebanne does describe, however, what he terms "massive Tswananization" occurring in the mid $20^{\text {th }}$ century: because of a forced relocation and compulsory schooling in Setswana, Sebirwa engaged in massive borrowing of Setswana lexical items and "phonological characteristics" (2000:194). Our fieldwork investigated the phonetic and phonological characteristics of the Sebirwa consonant system. The design was the same as the Setswana experiment reported above. Nine speakers participated. The results are shown in Figures 9, 10, and 11.

Figure 9 shows that in initial position, the contrast is between pre-voicing and very short-lag VOT. Unlike in Setswana, the voiceless stops have weak bursts that do not seem to be ejective. (See Figure 2.)

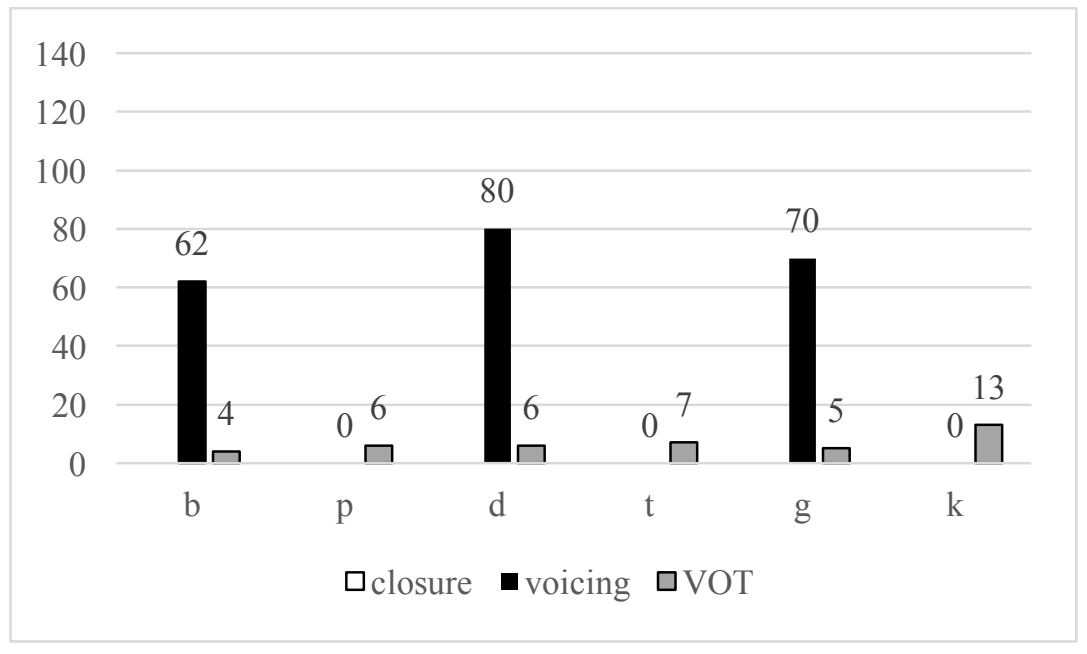

Figure 9. Duration (ms) of stops in phrase-initial position in Sebirwa. Data from Zsiga and Boyer (2017). 


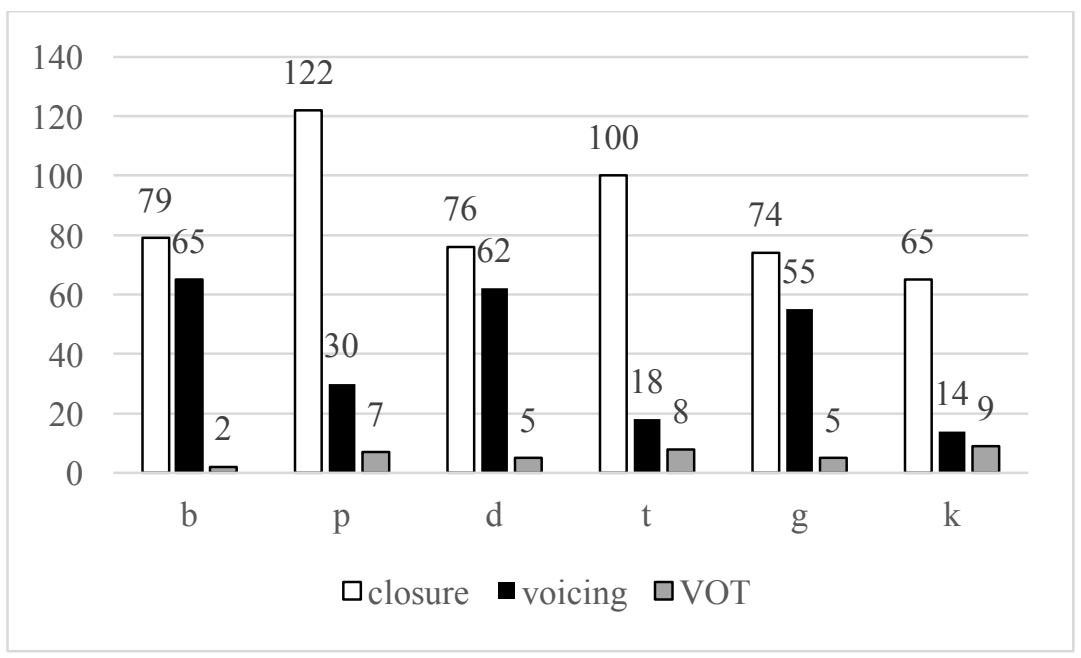

Figure 10. Duration (ms) of stops in phrase-medial position in Sebirwa . Data from Zsiga and Boyer (2017).

Figure 10 graphs closure, voicing, and VOT duration in intervocalic position. Here, while there is some perseverative voicing into the closure of voiceless stops, there is a clear difference in voicing duration between the voiced and voiceless series, unlike the data for Setswana (Figure 6). The closure duration for [p] does show extra length, perhaps an enhancement effect.

Figure 11 shows the results for post-nasal position. The stops $/ \mathrm{d} /$ and $/ \mathrm{g} /$ have a short closure duration that remains almost completely voiced. Conversely, /t/ and $/ \mathrm{k} /$ show active suppression of voicing, maintaining contrast. However, contra Chebanne (2000) and all expected cross-linguistic generalization), /b/ is devoiced, and not distinct from /p/. This pattern of devoicing is doubly anomalous. Due to aerodynamic considerations (Hayes 1999), both post-nasal position and labial place should favor voicing. As was noted above, post-nasal devoicing should not occur at all, and labials should be the least likely place of articulation to undergo devoicing.

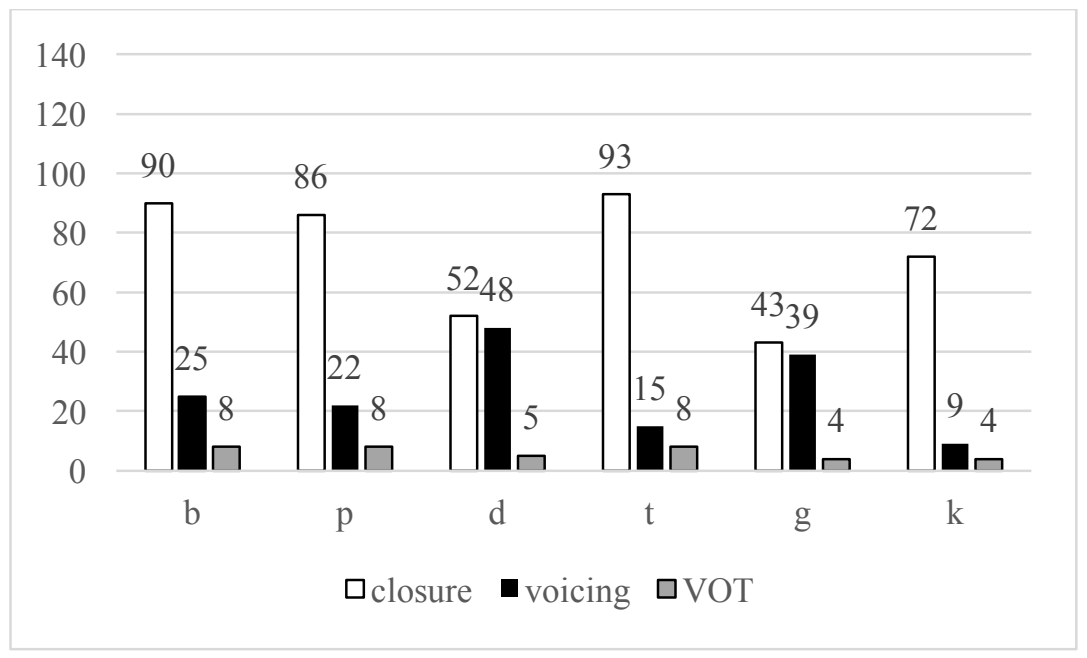

Figure 11. Duration (ms) of stops in phrase-nasal position in Sebirwa . Data from Zsiga and Boyer (2017).

How did this pattern come about, when according to Chebanne (2000) there is no post-nasal devoicing in Sebirwa? The most plausible explanation is that post-nasal devoicing was borrowed from Setswana as part of the "massive Tswananization" Chebanne describes. As a result of the skewed Setswana inventory, tokens of $/ \mathrm{mb} /$ becoming [mp] will be the most frequent. Because Setswana has no velar stop, there will be no instances of [g] alternating with [k]. The stop [d] does alternate with [t], as in [duba] "knead," [ntuba] "knead 
me," but tokens of this alternation will be less frequent, as [d] occurs only before a subset of vowels. In a phoneme frequency count of a corpus of 50,000 words of Setswana conversation, Palai and O'Hanlon (2004) find initial $/ \mathrm{b} /$ to be 2.25 times more frequent than initial $/ \mathrm{d} /$. They give no exact breakdown by word type, but most Setswana words that begin with /d/ are noun class markers, so would not occur in post-nasal position. The lateral /1/ also alternates with [t], but this alternation would also be less likely to be borrowed, as the relationship [1] [d] [t] does not hold in Sebirwa.

In Zsiga and Boyer (2017), we called the situation of Sebirwa in contact with Setswana "a natural experiment in learning an unnatural alternation." Phonologists set up artificial learning paradigms to test hypotheses about whether "unnatural" systems are impossible, hard, or easy to learn, but these experiments are difficult to design, and the data from these mini-experiments has been mixed. Here we have a learning situation, literally in the field, where speakers are exposed to data including an unnatural alternation (at least unnatural to Sebirwa speakers, who hear the alternation according to their own terms, as one of voicing). Yet, apparently, they learn the alternation. In this case, frequency of exposure matters more than phonetic naturalness.

Still, one would like to follow the experiment into the future. What will the next generation of Sebirwa speakers do? Can this pattern be stable? Will post-nasal devoicing spread to alveolars and velars? Or will the more natural pattern take over? Sadly, it seems likely we will not have the chance to find out, as it seems there is not going to be a next generation of Sebirwa speakers.

\section{Conclusion: Realism and abstraction, laryngeal and otherwise}

The data show that Sebirwa is a "true voice" language, in the terminology of Laryngeal Realism (Honeybone 2005), with a three-way contrast between Ø, [voice], and [spread glottis]. Surprisingly, it also has true post-nasal devoicing, due to borrowing from Setswana (and reinterpreting the labials of Setswana in its own terms), contra predictions of what is natural cross-linguistically. This borrowing provides support for theories such Evolutionary Phonology (Blevins 2006) and Emergent Features (Mielke 2008) that don't rely on phonetic grounding. The experiment, however, of whether this pattern can be stable is likely cut short.

Setswana is not a true voice language, and it does not exhibit post-nasal devoicing. With its three-way contrast, Setswana is not purely an "aspirating" language either. Rather than [+/- voice], Setswana contrasts [fortis/lenis] in addition to [SG].

Laryngeal Realism is right in that we should not default to calling every two-way stop contrast [+/voice]. Other dimensions are available, including the "strength" dimension originally proposed by Trubetzkoy (1939). Sometimes laryngeal realism also requires some phonological abstraction. In choosing features for laryngeal contrasts, the four criteria proposed by Clements et al. (2011) - cross-linguistic recurrence, formal simplicity, and comprehensiveness, in addition to phonetic definition - should be given equal weight.

\section{References}

Avery, Peter and William Idsardi. 2001. Laryngeal dimensions, completion, and enhancement. In T. A. Hall (Ed.), Distinctive Feature Theory. Berlin: Mouton de Gruyter.

Blevins, Juliette. 2006. A theoretical synopsis of Evolutionary Phonology. Theoretical Linguistics 32: 117-166.

Boersma, Paul and David Weenink. 2017. Praat: Doing phonetics by computer. [computer program] www.praat.org.

Boyer, One and Elizabeth Zsiga. 2013. Phonological devoicing and phonetic voicing in Setswana. In Olanike Ola Orie and Karen W. Sanders (Eds.), Proceedings of the 43rd Annual Conference on African Linguistics. Amherst, MA: Cascadilla Proceedings Project. pp. 82-89.

Chebanne, Anderson. 2000. The Sebirwa language: A synchronic and diachronic account. Pula: Botswana Journal of African Studies 14:186-95.

Chomsky, Noam and Morris Halle. 1968. The Sound Pattern of English. Cambridge, MA: MIT Press.

Clements, G.N., Alexis Michaud, \& Cédric Patin. 2011. Do we need tone features? In Elizabeth Hume, John Goldsmith, \& Leo Wetzels (Eds.), Tones and Features. Berlin: Mouton De Gruyter. pp. 3-24.

Coetzee, Andries and Rigardt Pretorius. 2010. Phonetically grounded phonology and sound change: The case of Tswana labial plosives. Journal of Phonetics 38: 404-421.

Cohn, Abigail. 2011. Features, segments, and the sources of phonological primitives. In G. N. Clements and R. Ridouane (Eds.), Where Do Features Come From? Amsterdam: John Benjamins. pp. 15-41.

Gallagher, Gillian. 2011. Acoustic and articulatory features in phonology: The case for [Long VOT]. The Linguistic Review 28(3):281-313. 
Gouskova, Maria, Elizabeth Zsiga, and One Tlale. 2011. Grounded constraints and the consonants of Setswana. Lingua 121:2120-2152.

Halle, Morris. and Kenneth Stevens. 1971. A note on laryngeal features. Progress Report of the MIT Research Laboratory in Electronics 100:198-213.

Hayes, Bruce. 1999. Phonetically driven phonology: The role of Optimality Theory and inductive grounding. In Mike Darnall et al. (Eds.), Functionalism and Formalism in Linguistics. Amsterdam: John Benjamins. pp. 243-285.

Hayes, Bruce. 1984. The phonetics and phonology of Russian voicing assimilation. In Mark Aronoff and Richard Oehrle (Eds.), Language Sound Structure. Cambridge, MA: MIT Press. pp. 318-328.

Hyman, Larry. 2001. On the limits of phonetic determinism in phonology: *NC revisited. In Elizabeth Hume and Keith Johnson (Eds.), The Role of Speech Perception in Phonology. New York: Academic Press. pp. 141-185.

Hyman, Larry. 2010. Do tones have features? UC Berkeley Phonology Lab Annual Report.

Hyman, Larry. 2011. The representation of tone. In Marc van Oostendorp, Colin J. Ewen, Elizabeth Hume and Keren Rice (Eds.), The Blackwell Companion to Phonology. New York: Blackwell Publishing.

Jakobson, Roman, Gunnar Fant and Morris Halle. 1952. Preliminaries to Speech Analysis: The Distinctive Features and their Correlates. Cambridge, MA: MIT Press.

Jun, S.-A. 1996. Asymmetrical prosodic effects on the laryngeal gesture in Korean. In Bruce Connell and Amalia Arvaniti (Eds.). Phonology and Phonetic Evidence: Papers in Laboratory Phonology IV. Cambridge, UK: Cambridge University Press. pp. 235-253.

Kingston, John. 2005. The phonetics of Athabasakan tonogenesis. In Sharon Hargus and Keren Rice (Eds.). Athabaskan Prosody. NY: John Benjamins. pp. 137-184.

Kingston, John and Randy Diehl. 1994. Phonetic knowledge. Language 70:419-454.

Kohler, Klaus. 1984. Phonetic explanation in phonology: The feature fortis/lenis. Phonetica 41:150-174.

Lombardi, Linda. 1991. Laryngeal Features and Laryngeal Neutralization. NY: Garland.

Maddieson, Ian. 1984. Patterns of sounds. Cambridge, U.K.: Cambridge University Press.

Mielke, Jeff. 2008. The Emergence of Distinctive Features. Oxford, U.K.: Oxford University Press.

Pater, Joe. 1999. Austronesian nasal substitution and other NC effects. In René Kager, Harry van der Hulst and William Zonneveld (Eds.), The Prosody-Morphology Interface. Cambridge, U.K. Cambridge University Press. pp. 310-343.

Palai, Esther Basadi and Laureen O'Hanlon. 2004. Word and phoneme frequency of occurrence in conversational Setswana: a clinical linguistic application. Southern African Linguistics \& Applied Language Studies 22:125-142.

Sole, Maria-Josep, Larry Hyman, and Kemmonye Monaka. 2010. More on post-nasal devoicing: The case of Shekgalagari. Journal of Phonetics 38:604-615.

Trubetzkoy, Nikolai. 1969 [1939]. Principles of phonology. Translated by Christiane Baltaxe. Berkeley CA: University of California Press.

Zsiga, Elizabeth, Maria Gouskova, and One Tlale. 2006. On the status of voiced obstruents in Tswana: Against *ND. In C. Davis, A. Deal, and Y. Zabbal (Eds.), NELS 36: Proceedings of the $36^{\text {th }}$ Meeting of the North East Linguistics Society. pp. 721-734.

Zsiga, Elizabeth and One Tlale Boyer. 2017. A natural experiment in learning an unnatural alternation: Sebirwa in contact with Setswana. In J. Kandybowicz and H. Torrence (Eds.), Africa's Endangered Languages: Documentary and Theoretical Approaches. Oxford: Oxford University Press. pp. 343-366.

Zsiga, Elizabeth, Jonathon Havenhill, One Tlale Boyer and Stacy Petersen. 2018. The labiocoronal fricatives of Setswna. ms, Georgetown University. 